
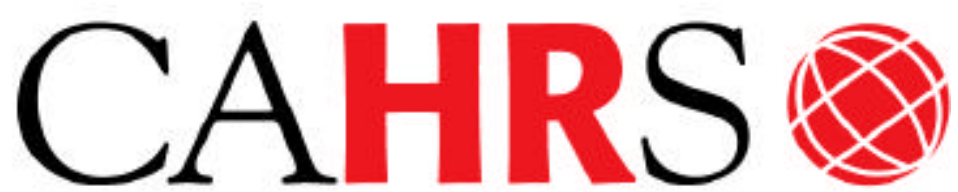

Center for Advanced Human Resource Studies
CAHRS / Cornell University 187 Ives Hall

Ithaca, NY 14853-3901 USA

Tel. 607 255-9358

www.ilr.cornell.edu/CAHRS/

VURAINGPAPER SEPIES

\title{
Strategy, Core Competence and HR Involvement as Determinants of HR Effectiveness and Refinery Performance
}

Blaine McCormick

Gary C. McMahan

W. Scott Sherman

Patrick M. Wright

Working Paper 97 - 16 


\title{
Strategy, Core Competence and HR Involvement as Determinants of HR Effectiveness and Refinery Performance
}

\author{
Patrick M. Wright \\ School of Industrial and Labor Relations \\ 393 Ives Hal \\ Cornell University \\ Ithaca, NY 14853-3901 \\ Phone: (607) 255-3429 \\ Gary C. McMahan \\ Department of Management \\ University of Texas at Arlington \\ Arlington, TX 76019 \\ Blaine McCormick \\ Seaver College \\ Business Administration Division \\ Pepperdine University \\ Malibu, CA 90263 \\ W. Scott Sherman \\ Department of Management \\ Texas A\&M University \\ College Station, TX 77843-4221 \\ (409) 845-1665

\section{Working Paper 97-16} \\ http://www.ilr.cornell.edu/cahrs
}

This paper has not undergone formal review or approval of the faculty of the ILR School. It is intended to make results of Center research available to others interested in preliminary form to encourage discussion and suggestions. 


\title{
Strategy, Core Competence and HR Involvement as Determinants of HR Effectiveness and Refinery Performance
}

\begin{abstract}
This study examined the impact strategy, core competence, and involvement of HR executives in strategic decision making on the refinery managers' evaluation of the effectiveness of HR and refinery performance among 86 U.S. petro-chemical refineries. Survey results indicated that higher involvement of $\mathrm{HR}$ in organizational strategy was strongly related to perceptions of HR effectiveness, and that the relationship was strongest to the extent that refineries pursued a product innovation strategy and viewed skilled employees as their core competence. HR involvement was unrelated to refinery performance, but was actually negatively related to the extent that refineries emphasized efficient production as their core competence.
\end{abstract}

The authors wish to thank Randall S. Schuler, Scott A. Snell, and Nate Bennett for their comments on a previous version of this paper. 


\section{Strategy, Core Competence and HR Involvement as Determinants of HR Effectiveness and Refinery Performance}

The increasingly global nature of competition requires that firms utilize all of their available resources in order to survive and succeed. This has resulted in an emphasis on the alignment of all functional activities of the firm (e.g., finance, marketing, operations, etc.) toward the achievement of strategic objectives. One consequence of this trend is that many have called for a new strategic role for the HR function (Dyer, 1984; Martell \& Carroll, 1995; Schuler, 1992; Ulrich, 1991). This role entails two major aspects. First, the HR executive should provide input into the firm's strategy in order to ensure that the firm has the human resource capabilities to implement it. Second, the HR function needs to ensure that the HR programs and practices are in place to effectively implement the strategy (Truss \& Gratton, 1994; Wright \& McMahan, 1992).

However, one impediment to effectively performing this role has been the fact that the HR function has been neither traditionally viewed nor empirically demonstrated to contribute to firm performance, and therefore, neither important nor effective (Carroll, 1991; Thornburg, 1991; Walker \& Bechet, 1991). This results in a vicious circle such that if strategic decision makers believe that the HR function does not contribute to firm performance or is not effective, they will fail to invite HR executives into the strategic decision making process. Because HR executives have no input into strategy, they may be unable to maximally contribute to performance. The purpose of this paper is to examine how the types of strategies used and the involvement of the HR executive impact manager's evaluation of the effectiveness of the HR function and operating unit performance in petro-chemical refineries.

In order to examine this relationship, we focused on the integration of HR and strategy in the operations of petro-chemical refineries. While much of the research on the strategic involvement of HR has focused on examining involvement at the corporate level (e.g., Huselid, 1993; Martell \& Carroll, 1994), this ignores the valuable strategic contributions of HR executives in the management of actual operating units. Thus, the purpose of our study was to examine the impact of HR involvement in strategic management at the level of the operating unit.

\section{Strategic Involvement of HR Executives}

An increasing number of studies have attempted to assess the linkage of HR and strategy processes. In an early study in the area, Golden and Ramanujam (1985) examined the link between HR and strategic decision making among ten firms. Based on their analysis of 
these firms, they posited four levels of linkage. They termed this first level the "Administrative Linkage," in which the role of the HR function consists of performing the administrative paper processing duties such as maintaining payroll, record keeping, and processing benefits claims. A second level of linkage was called the "One Way Linkage" where the HR function played a role in strategy implementation but having no impact on the formulation of firm strategies. The "Two Way Linkage," the third level of linkage, entailed the HR function contributing to both the strategy formulation and strategy implementation processes. In this level of linkage the HR department provided input to strategic decision makers regarding the strengths, weaknesses, opportunities and threats pertaining to the firm's human resources, and the strategic decision making team used this information in formulating the strategy. Then, based on the strategy, the HR function sought to develop and align HR policies, programs, and practices in a way that would support the implementation of the strategy. Finally, the most extensive level of linkage was termed the "Integrative Linkage." In the few firms with this level of linkage, the HR Executive is a member of the strategic decision making team. This ensures that the HR function participates throughout the strategy formulation process, and plays an integral role in the firm's competitive advantage.

Buller (1988), in a follow-up to the Golden and Ramanujam study, examined the strategic involvement of the HR function in strategy among 8 firms. He found that none of the firms exhibited the administrative linkage, 3 of the firms were at the one-way linkage level, 3 of the firms demonstrated the two-way linkage, and 2 firms displayed the integrative linkage. In addition, he found that the integration of strategic planning and human resources was more difficult among diversified firms, and that within these firms the HR - Strategic Planning link was often decentralized to the operating units.

In a recent study Huselid (1993) sought to examine the environmental determinants of human resource planning and strategic human resource management. While not specifically exploring the determinants of the level of involvement of HR in strategy, he did measure it, thus one can look to his data to examine this issue. Among his sample of 968 firms, he found that HR involvement in strategic business planning was positively related to organizational size, the sophistication of the firm's business planning processes, its use of human resource planning, and its use of strategic human resource management.

More recently, Martell and Carroll (1995) surveyed General Managers of 115 SBU's of 89 Fortune 500 companies regarding the extent to which HR was linked to the firm's strategy. They found that HRM and the strategic planning process were linked in between $44 \%$ and $69 \%$ of the companies, and that while the HR function was viewed as important to implementing 
business strategy, it was not as important as other functions. They also found that the integration of HRM and strategy processes was not related to the business unit's short term performance.

Finally, Bennett, Ketchen, \& Schultz (1995) examined the antecedents and consequences of strategic integration of HR among 148 manufacturing firms in Louisiana. These authors found that firms classified as Analyzers exhibited a greater level of strategic integration than did either Defenders or Prospectors. They also found that the integration of HR and strategy was greater when top managers viewed employees as a strategic resource. Regarding the consequences of strategic integration, they observed that it was positively related to turnover, but negatively related to top managers' evaluation of the effectiveness of the HR function and unrelated to sales per employee and perceived profitability.

Based on this literature, it appears that very little is known regarding how the level of strategic involvement of the HR function is related to the perceived effectiveness of the function. Numerous authors have called for increasing the extent to which HR managers are involved in the strategic management of the firm, yet very little data exists with regard to the effectiveness of it. In fact, of the four studies on the topic, only two have even attempted to examine the outcomes of strategic involvement. Of those two, neither found any relationship between involvement and firm performance, and one (Bennett et al., 1995) actually found a negative relationship. Thus, before continuing calls for increasing the strategic involvement of $\mathrm{HR}$, it may be necessary to examine if, in fact, line managers perceive that such involvement is associated with the effectiveness of the function.

In addition to the perception of effectiveness, involvement of the HR executive in refinery strategy management should be related to the refinery's performance. The HR executive should have detailed knowledge regarding the human resource capabilities in terms of both cultural and functional differentiation. This can provide input into the viability and desirability of various strategic alternatives. In addition, the HR executive should have specific knowledge of the HR issues that directly impact refinery performance given a strategic choice. His/her involvement in the strategic management of the refinery should ensure that these issues are adequately recognized and dealt with in a way that enables the refinery to perform better than refineries where these issues are ignored.

This leads to the following hypotheses:

Hypothesis 1a: HR Involvement will be positively related to operations managers' perceptions of the effectiveness of the HR function. 
Hypothesis 1b: HR Involvement will be positively related to the refinery's financial performance.

\section{Strategy, HR Involvement, and HR Effectiveness}

While the idea that $\mathrm{HR}$ involvement in the strategic management process is thought to be effective in all cases, there is reason to believe that it might be more important for certain firm strategies. For example, as discussed above, Bennett et al. (1995) found that strategic involvement was greater when top managers viewed people as a strategic resource. This relationship between the view of employees as a strategic resource and the strategic involvement of the HR function might stem from differing required levels of involvement depending upon the strategy. For the sake of this study, we operationalized the refinery strategy in terms of its product/market strategy, and assessed the extent to which the refinery emphasized product/customer breadth (i.e., focusing on large but stable product variety and wide bases of customers) and product innovation (meeting fast-changing customer needs through frequent product and process innovations).

Typologies of manufacturing strategies note that some strategies such as cost strategies often seek to minimize the role of employees through limiting their discretionary behavior. A product breadth strategy deemphasizes the importance of employees as the goal is to produce a consistent, but wide variety of products at a low cost. Thus, the orientation is more toward manufacturing efficiency resulting in a more tightly coupled production process. The organizational logic behind such a strategy is to design narrow jobs requiring low skill levels, thus making employees an easily replaceable component to the production process (Hayes, Wheelwright, \& Clark, 1988; MacDuffie, 1995; Snell \& Dean, 1992; Youndt, Snell, Dean, \& Lepak 1995). A strategy that does not emphasize the contribution of employees should not require an extensive level of strategic involvement of the HR function. In this setting the role of the HR function is primarily one of handling administrative matters related to employment.

On the other hand, some strategies seek to maximize the contribution of employees through requiring high levels of discretionary behavior (MacDuffie, 1995). Strategies such as flexible production which strives to minimize buffers in the production process by minimizing lead times and scaling production up and down quickly (Womack, Jones, \& Roos, 1990). This is similar to a product innovation strategy that seeks to quickly and frequently modify products and procedures to adapt to changing customer needs. With regard to product strategies, Sanchez (1995) noted that dynamic product markets require flexibility in redefining product strategies, reconfiguring chains of resources, and redeploying resources effectively. Such strategies entail focusing on continuous improvement and helping technology to be used more 
effectively, i.e., "giving wisdom to the machine" (Monden, 1983). Thus, effective implementation of this strategy requires skilled and knowledgeable workers who are motivated to contribute their discretionary effort toward the attainment of organizational goals (MacDuffie, 1995). The dynamic nature of the products and markets requires more frequent changes in HR practices. Thus, relative to the product breadth strategy, then, the integration of HR and strategy becomes significantly more important. When the HR executive is highly involved, s/he can provide input regarding employee capabilities into the evaluations of proposed changes, and additionally will then have more specific and detailed information regarding the HR issues stemming from those changes. Thus, one would expect that the relationship between HR involvement and both operations managers' perceptions of HR effectiveness and refinery performance should differ across the different strategies.

This leads to the following hypotheses:

Hypothesis 2a: The relationship between HR involvement and operations managers' perceptions of HR Effectiveness will be moderated by the product innovation strategy such that the relationship will be stronger for refineries emphasizing a product innovation, relative to those that do not. This relationship will not be observed for the product breadth strategy.

Hypothesis $\mathbf{2 b}$ : The relationship between HR involvement and refinery performance will be moderated by the product innovation strategy such that the relationship will be stronger for refineries emphasizing a product innovation, relative to those that do not. This relationship will not be observed for the product breadth strategy.

\section{Core Competence, HR Involvement, and HR Effectiveness}

As opposed to the product/market strategy, the core competence of a firm is a bundle of skills and technologies that represents the sum of learning across individual skill sets and individual organizational units. A core competence provides a competitive advantage through being competitively unique and making a contribution to customer value or cost (Prahalad \& Hamel, 1990). Long \& Vickers-Koch (1995) expand the idea of core competences to core capabilities. They distinguish these two by noting that "...competencies relate to the skills, knowledge, and technological know-how that give a special advantage at specific points of the value chain, which, in combination with the strategic processes that link the chain together, form core capabilities," (p. 12). In essence, the three core competences we identified in this study refer to three different points in the value chain. 
In this study we identified 3 possible core competencies of petro-chemical refineries: skilled workforce, efficient production, and new business development. The skilled workforce competence described refineries in terms of the extent to which they characterized their core competence as attracting, retaining, and developing a skilled set of employees, or the input to the value chain. The efficient production competence characterized the extent to which refineries achieved competitive advantage through developing an efficient production process staffed by a highly motivated set of employees, i.e., the throughput component of the value chain. Finally, the new business development competence described the extent to which refineries characterized their ability to develop new products, new markets, and new business contracts as a core competence, focusing on the output end of the value chain.

As with the product/market strategies, one would expect that the importance of HR involvement in strategy depends upon the perceived core competence of the facility. The skilled workforce core competence seems to require that the HR function play an integral role in the management of the core competence. This core competence clearly has an HR orientation. Where a facility emphasizes the skilled workforce as its core competence, the involvement of the HR executive in strategic management should be strongly positively related to the operations manager's perception of the function's effectiveness relative to refineries that do not emphasize this competence.

Refineries also seem to differ in the extent to which they emphasize an efficient production process as a core competence. Efficient production can be achieved largely through technology such as Computer-Assisted Design and Development (CADD), Computer Integrated Manufacturing (CIM), and Electronic Data Integration (EDI) systems (Sanchez, 1995). This core competence seems to have an engineering orientation. However, such systems also should require a motivated workforce to control the processes, again recognizing the role of the $\mathrm{HR}$ function in managing at least one aspect of this core competence. One would expect that HR involvement would be somewhat important in refineries emphasizing the efficient production process. Thus, a weaker (relative to the skilled employee competence), but still positive relationship should be observed between HR involvement and both HR effectiveness and refinery performance in refineries emphasizing the efficient production process relative to those not emphasizing this as a core competence.

Finally, the new business development competence seems to emphasize a focus on the customer, rather than a focus on operations employees as a source of competitive advantage. This core competence seems to have a marketing orientation. In such a situation, the importance of HR involvement should not differ based on the extent to which the refinery 
emphasizes this core competence. Thus, one would expect that the relationship between HR involvement in strategy and both HR effectiveness and refinery performance should not differ based on the extent to which the refinery emphasizes new business development. This leads to the following hypothesis:

Hypothesis 3a: Refineries' emphases of skilled workforce or efficient production should moderate the relationship between HR involvement and HR effectiveness such that stronger positive relationships will be observed when these core competences are emphasized relative to when they are not. This moderating relationship will not be observed for the emphasis of new business development.

Hypothesis 3b: Refineries' emphases of skilled workforce or efficient production should moderate the relationship between HR involvement and refinery performance such that stronger positive relationships will be observed when these core competencies are emphasized relative to when they are not. This moderating relationship will not be observed for the emphasis of new business development.

\section{Method}

\section{Sample}

As previously discussed, most of the work on the relationship between HR and strategy has been focused at the corporate level (Golden \& Ramanujam, 1985; Buller, 1988). While providing useful information, it often misses the ways in which HR can contribute to organizational performance at the level where production of a product or service takes place. An alternative approach would be to examine the linkage between HR and strategy at the place where they are implemented: the specific site (MacDuffie, 1995).

Thus, our sample was drawn from the population of petro-chemical refineries in the United States. Surveys were mailed to both operations (refinery or operations managers) and human resources (HR manager or Employment Coordinator) employees at all 194 petroleum refineries in the United States as listed by the Department of Energy's Energy Information Administration as part of a larger study on the impact of HR practices on refinery performance (Wright, McCormick, Sherman, and McMahan, 1995). Four of the refineries had ceased operations, and the surveys were returned, resulting in a potential sample of 190.

All of the results reported here are based on the surveys of the operations managers. The survey asked respondents to reveal the refinery strategy in terms of product mix, their evaluation of the skills and motivation of the operator workforce, the involvement of the HR 
executive in the strategic management of the facility, their perception of the effectiveness of the HR function, and the refinery's performance in terms of profit margin during 1993 as well as annual profit growth and annual sales growth over the 1988-1993 period. Surveys were returned from 86 refineries for a response rate of $45 \%$.

\section{Measures}

All of the items for the measures reported here are provided in the appendix.

Product/Market Strategy. The survey contained 11 items assessing a variety of strategic activities with regard to the products and customers of the refineries. A principal components factor analysis with Varimax rotation revealed two interpretable factors with eigenvalues greater than 1 explaining $56 \%$ of the variance. Product Breadth Strategy was assessed with five items regarding the breadth of products and customers. The coefficient alpha for this scale was .72. Product Innovation Strategy was assessed with five items measuring the extent to which the facility changes products in response to changing customer needs. The coefficient alpha for this scale was .60 .

Core Competencies. The survey contained 7 items assessing a variety of potential sources of core competence. A principal components factor analysis of this scale revealed three interpretable factors with eigenvalues greater than 1 and explaining $71 \%$ of the variance. Skilled Employees contained two items dealing with the attraction, retaining, and development of skilled employees. This scale had an alpha of .69. Efficient Production contained two items, one concerning the efficiency of the production process and the other tapping the motivation of employees. This scale exhibited an alpha of .70 New Business Development contained 3 items on the development of market opportunities, business contracts, and products. The coefficient alpha for this scale was .57 .

HR Involvement. The involvement of HR in strategic management of the refinery was assessed with 7 items that assessed the extent to which the top HR person in the facility engaged in activities such as providing input into the long range strategy and developing HR systems to implement facility strategy. The coefficient alpha for this scale was .92.

HR Effectiveness. The effectiveness of the HR function was assessed with 4 items regarding the extent to which the operations manager felt that the department performed well, met his or her expectations, and was a value added/bottom line contributor to the business. This scale was adapted from Tsui (1990). The coefficient alpha for this scale was .83.

Financial Performance. Financial performance of the refinery was assessed with 3 items assessing the profit margin during 1993 and profit and sales growth over the 1988-1993 
time period which was the 5-year period preceding the survey. This scale is similar to that used by Terpstra and Rozell (1993) and exhibited an alpha of .67.

\section{Results}

The means, standard deviations and inter-correlations of the variables are reported in Table 1.

Table 1. Table of Means, Standard Deviations, and Inter-correlations.

\begin{tabular}{lcccccccccr} 
Variable & Mean & SD & 1 & 2 & 3 & 4 & 5 & 6 & 7 \\
\hline 1. Breadth Strategy & 3.49 & 1.27 & - & & & & & & \\
2. Innovation Strategy & 4.07 & .95 & 41 & - & & & & & & \\
3. Skilled Employees & 5.39 & 1.11 & 12 & 36 & - & & & & & \\
4. Efficient Production 5.34 & 1.11 & 06 & 36 & 41 & - & & & & \\
5. Business Development & 4.30 & .99 & 23 & 43 & 29 & 26 & - & & \\
6. HR Involvement & 27.51 & 10.72 & 22 & 30 & 37 & 36 & 28 & - & \\
7. HR Effectiveness & 16.06 & 4.90 & 21 & 31 & 39 & 39 & 25 & 79 & - \\
8. Financial Performance & 2.85 & 1.44 & -07 & 09 & -17 & 05 & 05 & -10 & -10 & -
\end{tabular}

$r>22, \underline{p}<.05$

Decimal points have been omitted.

Hypothesis 1a stated that the level of involvement of the HR executive in strategy would be positively related to the operations managers' evaluation of the effectiveness of the HR function. As can be seen in Table 1, the correlation between involvement and effectiveness was .79 ( $\underline{p}<.001)$, supporting this hypothesis.

Hypothesis $1 \mathrm{~b}$ stated that the level of involvement of the HR executive in strategy would be positively related to refinery performance. As can be seen in Table 1, the correlation between involvement and refinery performance was -.10 (n.s.), showing no support this hypothesis.

Hypothesis 2a stated that the product innovation strategy would moderate the relationship between HR involvement and HR effectiveness. This hypothesis was tested through hierarchical regression, regressing the effectiveness variable on product innovation and HR involvement in step 1, and the interaction in step 2. As can be seen in Table 2, strategy and involvement explained $62 \%$ of the variance in effectiveness, and the interaction explained an incremental $2 \%(\underline{p}<.05)$. The positive weight for the interaction term indicates support for the hypothesis. It was also hypothesized that this relationship would not be observed for the product breadth strategy. As can be seen in Table 2, the breadth strategy and HR involvement 
explained $62 \%(\underline{p}<.01)$ of the variance in HR effectiveness, but the interaction explained a nonsignificant $1 \%$. Thus, Hypothesis $2 a$ was supported.

\section{Table 2. Regression Results Regressing HR Effectiveness and Refinery Performance on Strategy, HR Involvement, and the Interaction.}

\begin{tabular}{|c|c|c|}
\hline & $\mathrm{R}^{2}$ Change $\mathrm{B}$-Weight & $\mathrm{R}^{2}$ Change $\mathrm{B}-$ Weight \\
\hline & $\underline{H R}$ Effectiveness $^{a}$ & $\underline{R e f i n e r y ~ P e r f o r m a n c e ~}^{b}$ \\
\hline Step 1 & $.62^{\star \star \star}$ & .01 \\
\hline Product Innovation Strategy & -1.22 & .19 \\
\hline HR Involvement & .07 & .02 \\
\hline Step 2 & $.02^{*}$ & .00 \\
\hline Innovation X Involvement & $.06^{*}$ & -.01 \\
\hline Step 1 & $.62^{\star \star \star}$ & .03 \\
\hline Product Breadth Strategy & -.69 & .42 \\
\hline HR Involvement & .25 & .02 \\
\hline Step 2 & .01 & .00 \\
\hline Breadth X Involvement & .03 & -.01 \\
\hline 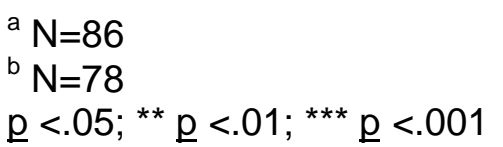 & & \\
\hline
\end{tabular}

Hypothesis $2 \mathrm{~b}$ stated that the product innovation strategy would moderate the relationship between involvement and refinery performance. This hypothesis was tested through hierarchical regression, regressing refinery performance on product innovation and HR involvement in step 1, and the interaction in step 2. As can be seen in Table 2, strategy and involvement explained $1 \%$ of the variance in performance, and the interaction explained an incremental $0 \%$ (both n.s.). It was also hypothesized that the moderating relationship would not be observed for the product breadth strategy. As can be seen in Table 2, product breadth and HR involvement explained $3 \%$ of the variance in performance, and the breadth by involvement interaction explained an incremental $0 \%$ (both n.s.). Thus, no support was demonstrated for Hypothesis $2 b$.

Hypothesis 3a stated that the refineries' emphases of a skilled workforce or efficient production should moderate the relationship between HR involvement and HR effectiveness such that stronger relationships will be observed when these core competences are emphasized relative to when they are not. This hypothesis was tested with three separate regression equations, each one regressing $\mathrm{HR}$ effectiveness on $\mathrm{HR}$ Involvement and the core competence factor (skilled employees, efficient production, and new business development) in 
the first step, and the HR involvement by core competence interaction in the second step. As can be seen in Table 3, in each of the equations, the core competence and involvement variables explained over $62 \%(\underline{p}<.01)$ of the variance in effectiveness. The skilled employees by involvement interaction explained an incremental $3 \%(\underline{p}<.05)$ of the variance in effectiveness, and the significant positive weight for the interaction term demonstrated support for the hypothesis. However, as can be seen in Table 3, the interaction terms for efficient production by HR involvement and new business development by HR involvement did not explain any significant incremental variance in HR effectiveness. Thus, only partial support was demonstrated for this hypothesis.

Table 3. Regression Results Regressing HR Effectiveness and Financial Performance on Core Competences, HR Involvement and the Interaction

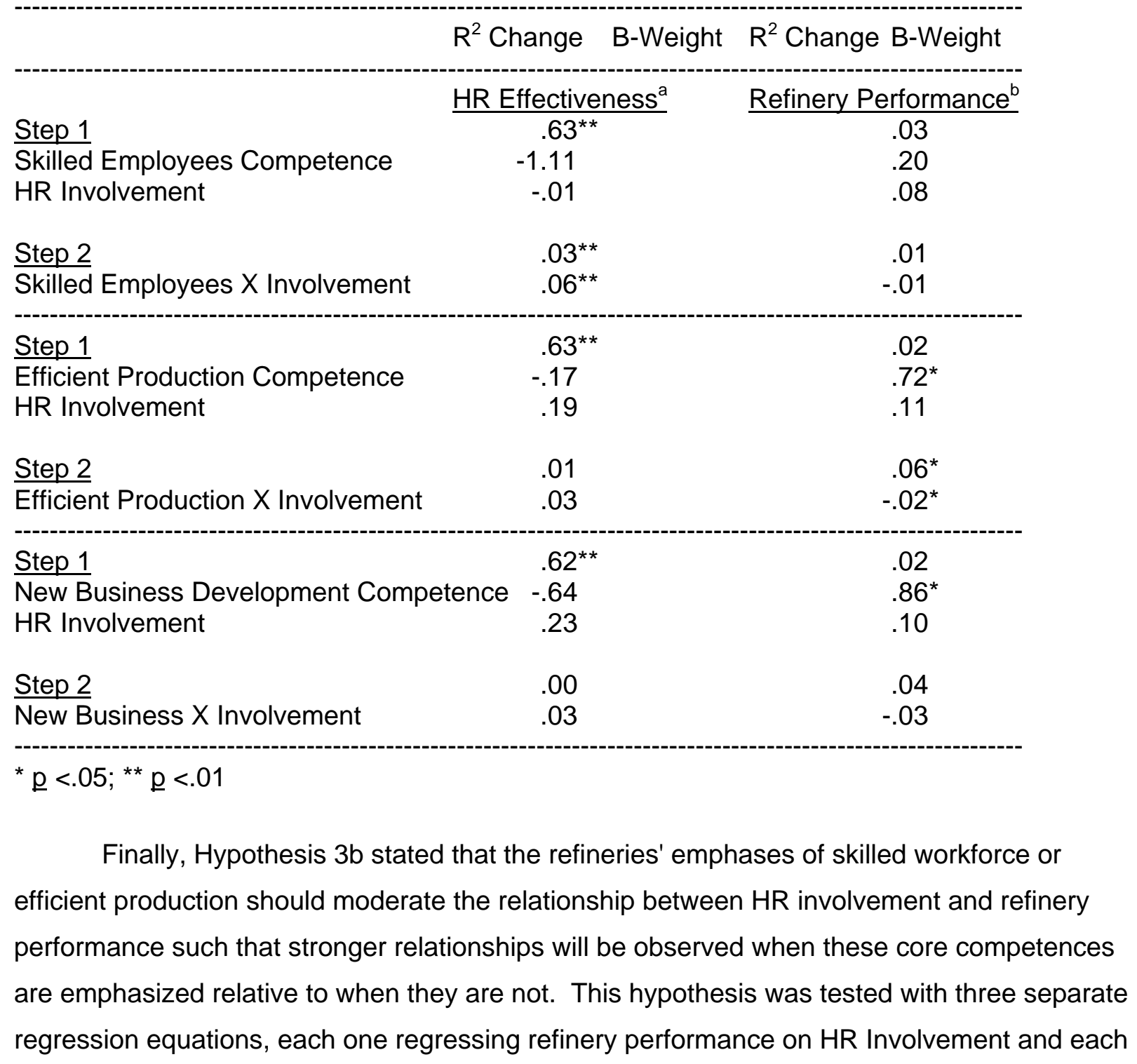


core competence factor (skilled employees, efficient production, and new business development) in the first step, and the HR involvement by core competence interaction in the second step. As can be seen in Table 3, the core competences and HR involvement variables explained a non-significant $2 \%$ or $3 \%$ of the variance in refinery performance in each case. The skilled employees by involvement interaction explained an incremental 1\% (n.s.) of the variance in effectiveness. However, the efficient production by involvement interaction explained an incremental $6 \%(\underline{p}<.05)$. In addition, the new business by involvement interaction explained a marginally significant $4 \%(\underline{p}=.08)$ in refinery performance. The negative weight for the interaction terms in both cases indicate that HR involvement is, in fact, detrimental to the performance of refineries with these core competences.

\section{Discussion}

Although many researchers have called for the increased involvement of HR executives in strategic management (Dyer, 1983; Schuler, 1992; Snow \& Snell, 1992; Truss \& Gratton, 1994; Wright, McMahan, \& McWilliams, 1994), very little research has examined the consequences of such involvement. The results of this study indicate that such involvement currently results in both positive and negative outcomes.

One positive outcome is that operations managers among petro-chemical refineries perceive value in having the HR executive involved in the strategy of the refinery. In contrast to the results observed by Bennett et al. (1995) who found a negative relationship between HR involvement and HR effectiveness, the strong correlation between HR involvement and perceptions of HR effectiveness in this study point to the fact that operations managers highly evaluate the HR function when the HR executive is heavily involved in strategic decision making. Additionally, the interactions indicate that this relationship is even stronger when refineries are pursuing product innovation strategies and when managers perceive skilled employees as the core competence. Thus, the results seem to demonstrate support for the increasingly strategic role of HR executives in petro-chemical refineries.

However, less optimistic results are observed when examining refinery financial performance as the dependent variable. Both Martell \& Carroll (1995) and Bennett et al. (1995) found no relationship between the involvement of the HR executive in strategic management and business unit performance. The results observed in this study are even less supportive of calls for this type of involvement. Involvement of the HR executive was unrelated to refinery performance in a bivariate sense. In addition, under the engineering-oriented efficient production core competence, high involvement of the HR executive negatively impacted refinery 
performance. This relationship was also observed (albeit marginally significant) with regard to the new business development competence as well.

Similar to the explanation offered by Bennett et al., (1995), this negative relationship may stem from HR executives being thrown into a strategic role for which they might not have yet developed the necessary skills. Ulrich and Yeung (1989) identified four sets of skills required by HR executives to effectively perform their strategic partner role: business competence, integration competence, professional/technical knowledge, and ability to manage change. Recent research has indicated that HR executives perceive weaknesses in certain strategic skills among the HR professionals comprising their firms (McMahan, Mohrman, \& Lawler, 1995). This is not surprising given the fact that calls for this role are barely more than 10 years old and that to date, very little empirical research exists regarding exactly how HR practices can be effectively aligned with strategy. Thus, it may be that HR executives are being provided the opportunity to participate in the strategic management of refineries, but because they have not yet developed the knowledge and skills regarding the HR needs associated with and HR practices necessary to implement these strategies, the refinery's performance suffers.

However, two limitations of this study must be noted. First, due to the cross-sectional nature of this study, none of the relationships observed should be assumed to be causal. In fact, it may be that poorly performing refineries have only relatively recently recognized the need to involve HR in strategic decision-making. On the other hand, refineries that have been performing well through emphasizing the efficient production or new business development competences might not yet sense the need for such HR involvement. Thus, these results should be interpreted with caution, and future research should attempt to tease out the true causal relationships.

Second, because the relationships reported are all from one survey, the possibility of percept-percept relationships must be acknowledged. However, this type of relationship is only problematic when assessing bivariate relationships (i.e., the correlation between HR involvement and HR effectiveness). The bulk of our findings are with regard to how such relationships are dependent upon production strategy or core competence. These relationships were tested with interaction terms, and these results are not a function of percept-percept relationships.

In conclusion, this study demonstrates that HR executives who are highly involved in the strategic management of petro-chemical refineries are associated with operations managers' positive evaluations of the HR function. However, the impact of such involvement on refinery performance is less clear, and in fact, might be negative. In light of other research that has 
failed to demonstrate a positive relationship between HR involvement and business unit performance (Bennett et al., 1995; Martell \& Carroll, 1995), it appears that many HR executives currently lack the skills necessary to fulfill their role as a strategic partner. Certainly this points to the need for additional research on the role of the HR function in firm performance so that in the future HR's potential contribution to firm performance might be fully realized. 


\section{References}

Bennett, N., Ketchen, D., \& Schultz, E. 1995. Antecedents and consequences of human resource integration with strategic decision making. Working paper, Louisiana State University.

Buller, P. 1988. Successful partnerships: HR and strategic planning at eight top firms. Organizational Dynamics, 17: 27-42.

Carroll, S. 1991. The new HRM roles, responsibilities, and structures. In R.S. Schuler,(Ed.), Managing HR in the information age.. Washington, DC: SHRM/BNA Books, Inc. 204226.

Dyer, L. 1984. Studying human resource strategy: An approach and an agenda. Industrial Relations, 23:156-169.

Golden, K. \& Ramanujam, V. 1985. Between a dream and a nightmare: On the integration of the human resource management and strategic business planning processes. Human Resource Management, 24: 429-452.

Hayes, R., Wheelwright, S. \& Clark, K. 1988. Dynamic Manufacturing: Creating the Learning Organization, New York, NY: Free Press.

Huselid, M. 1993. The impact of environmental volatility on human resource planning and strategic human resource management. Human Resource Planning, 16(3): 35-51.

Long, C., \& Vickers-Koch, M. 1995. Using core capabilities to create competitive advantage. Organizational Dynamics, Summer, 7-22.

MacDuffie, J. (1995). Human resource bundles and manufacturing performance: Organizational logic and flexible production systems in the world auto industry. Industrial and Labor Relations Review, 48, 197-221.

Martell, K. \& Carroll, S. (1995). How strategic is HRM? Human Resource Management. 34: 253-267.

McMahan, G., Mohrman, S., \& Lawler, E. 1995. The current practice of human resource management: A survey of the changing human resource function. Working Paper, Center for Effective Organizations, University of Southern California.

Monden, Y. 1983. Toyota Production System. Norcross, GA: Institute of Industrial Engineers.

Prahalad, C. \& Hamel, G. 1990. The core competence of the corporation. Harvard Business Review, May-June, 68(3): 79-91.

Sanchez, R. 1995. Strategic flexibility in product competition. Strategic Management Journal, 16: 135-159.

Schuler, R. 1992. Strategic Human Resource Management: Linking the people with the strategic needs of the business. Organizational Dynamics, Summer, 18-31. 
Snell, S., \& Dean, J. 1992. Integrated Manufacturing and human resource management: A Human capital perspective. Academy of Management Journal, 35: 467-504.

Snow, C., \& Snell, S. 1992. Staffing as strategy. In N. Schmitt and W. Borman (Eds.) Personnel Selection, Vol. 4, San Francisco: Jossey Bass.

Terpstra, D., \& Rozell, E. (1993). The relationship of staffing practices to organizational level measures of performance. Personnel Psychology, 46: 27-48.

Thornburg, L. 1991. HR executives focus on strategic partner role. HRMagazine, July, 62-63.

Truss, C. \& Gratton, L. 1994. Strategic human resource management: A conceptual approach. International Journal of Human Resource Management, 5(3): 663-686.

Tsui, A. 1990. A multiple constituency model of organizational effectiveness: An empirical examination at the human resource subunit level. Administrative Science Quarterly, 35: 458-483.

Ulrich, D. 1991. Using human resources for competitive advantage. In R. Kilmann, I. Kilmann, and Associates (Eds.) Making Organizations Competitive. San Francisco, CA: JosseyBass.

Ulrich, D., \& Yeung, A. 1989. A shared mindset. Personnel Administrator, March, 38-45.

Walker, J. \& Bechet, T. 1991. Defining effectiveness and efficiency measures in the context of human resource strategy. In R. Niehaus \& K. Price (Eds.), Bottom line results from strategic human resource planning, New York, NY: Plenum Press, 235-246.

Wernerfelt, F. 1984. A resource based view of the firm. Strategic Management Journal, 5: 171180.

Womack, J. Jones, D. \& Roos, S. 1990. The machine that changed the world. New York, NY: Rawson-MacMillan.

Wright, P. M., \& McMahan, G. C. 1992. Alternative theoretical perspectives for strategic human resource management. Journal of Management, 18: 295-320.

Wright, P., McMahan, G., \& McWilliams, A. 1994. Human resources as a source of sustained competitive advantage: A resource-based view. International Journal of Human Resource Management, 5: 299-324.

Wright, P., McCormick, B., Sherman, S., \& McMahan, G. 1995. The role of human resource practices in petro-chemical refinery performance. Paper presented at the Academy of Management Meeting, Vancouver, BC.

Youndt, M., Snell, S., Dean, J., \& Lepak, D. 1995. Human resource management, manufacturing strategy, and firm performance. Paper presented at the Academy of Management Meeting, Vancouver, BC. 


\section{Appendix}

\section{Strategic Involvement of HR}

1. Provide input into the facility's long-range strategic planning.

2. Meet with the facility manager to discuss HR issues.

3. Meet with the facility manager to discuss how HR can support the facility's long-range strategy.

4. Propose innovative HR programs to enhance competitiveness.

5. Identify future HR issues that could help or hinder future competitiveness.

6. Develop HR systems to implement facility strategies.

7. Revise existing HR systems to be supportive of facility strategies.

\section{Facility Strategy}

\section{Product Breadth}

1. Our facility offers a narrow range of products $(R)$.

2. The characteristics of our products differ a great deal from one another.

3. Our firm sells to a wide variety of customers.

4. The needs of our customers are very similar to one another $(R)$.

5. Our firm offers many different products to customers.

Product Innovation

1. Our facility establishes and maintains a stable product market posture (R).

2. Our firm is at the forefront of innovation and development.

3. Our business procedures have changed several times in past years.

4. The characteristics of our products are modified frequently.

5. The needs of our customers vary quite a bit from one year to the next.

\section{Core Competence}

Skilled Employees

1. Attracting and retaining competent employees.

2. Developing necessary skills among employees.

Efficient Production

1. Developing efficient production processes.

2. Improving employee motivation and morale.

New Business Development

1. Securing new business contracts.

2. Perceiving new market opportunities and threats.

3. Developing new products. 


\section{Effectiveness of HR}

1. Overall, to what extent do you feel your HR department is performing its job the way you would like it to be performed?

2. To what extent has this department met your expectations in its human resource management roles and responsibilities?

3. If you had your way, to what extent would you change the manner in which the HR department does its job?

4. To what extent is the HR function a value added/bottom line contributor to the business? 


\section{Human Resources and Intangible Resources}

Recent research in strategic management as focused on how firms develop and exploit resources under their control as a source of competitive advantage. This view of strategy has been termed the "resource-based view of the firm," (Barney, 1991; Mahoney \& Pandian, 1991; Wernerfelt, 1984) and has resulted in numerous research efforts attempting to identify the types of resources that can provide competitive advantage.

According to Wernerfelt a resource is "anything which could be thought of as a strength or weakness of a given firm...those tangible assets which are tied semipermanently to the firm" (1984: 172). Barney expands this definition to include "all assets, capabilities, organizational processes, firm attributes, information, knowledge, etc. controlled by a firm that enable the firm to conceive of and implement strategies that improve its efficiency and effectiveness" (1991: 101). According to Barney, resources fall into three categories: physical capital resources, human capital resources, and organizational capital resources. Examples of physical capital resources are the firm's plant and equipment, technology and geographic location. Human capital resources include characteristics such as the experience, judgement, and intelligence of the individual managers and workers in the firm. Organizational capital resources consist of such things as the firm's structure, planning, controlling and coordinating systems, and the informal relations among groups within the firm and between the firm and other firms in its environment.

A further elaboration of resources has developed regarding "intangible resources." Coyne (1986) argued that sustained competitive advantage could stem from four sources of capability differential: functional differential, cultural differential, positional differential, and regulatory differential. The first two sources of sustained competitive advantage lie among the firm's human resources. Functional differential results from the knowledge, skills, and experience of employees and others in the value chain. It is the intangible resources that results in distinctive competencies, i.e., those capabilities that set it apart from its competitors. Cultural differential incorporates the habits, attitudes, beliefs and values which permeate the individuals and groups which comprise the organization. Cultural differential both sets the firm apart from others and binds members of the firm together. These two resource differentials provide the foundation for organizational competencies (Hall, 1992), and these competencies can serve as a source of competitive advantage (Prahalad \& Hamel, 1992).

These categorizations of firm resources illustrate the importance of a firm's human resources in views of competitive advantage. Wright, McMahan \& McWilliams (1994) defined human resources as "the pool of human capital under the firm's control in a direct employment 
relationship." This definition is quite similar to Barney's (1991) conceptualization of human capital resources as well as Coyne's (1986) concept of functional differential. Additionally, Barney's (1991) inclusion of examples of organizational resources such as informal relationships among individuals and groups in the firm and Coyne's (1986) concept of cultural differential (e.g., habits, values, and beliefs of individuals and groups in the firm) are both quite difficult to conceive of without reference to the firm's human capital pool.

In addition, the potential for a firm's human resources to provide a source of competitive advantage has substantial support. Wright et al. (1994) and Lado and Wilson (1994) both conceptually demonstrated the potential for a firm's human resources to contribute to competitive advantage. In addition, Hansen and Wernerfelt (1991) found that aspects of firms human and organizational resources explained significantly more variance in firm performance than did industry or economic factors. Finally, recent research has demonstrated a relationship between various HR practices and firm performance (Arthur, 1994; Huselid, 1995; Ichniowski, Shaw, \& Prennushi, 1994; Snell \& Youndt, 1995; Youndt, Snell, Dean, \& Lepak, 1995).

This illustrates the potentially important role that the HR function can play in developing and sustaining sources of competitive advantage. Many potential sources of competitive advantage are inherent in the people or human resources that comprise the firm. The HR function's primary role consists of the management of those resources through identifying, developing, or maintaining the sources of functional and cultural differentiation, particularly through ensuring that these complement or influence the choice of operating unit strategy. Thus, the potential for a firm's human resources and HR practice to provide a source of competitive advantage points to the likely importance of involving the HR function in strategic decision making. 


\section{REFERENCES}

Arthur, J. 1992. The link between business strategy and industrial relations systems in American steel minimills. Industrial and Labor Relations Review. 45: 488-506.

Arthur, J. 1994. Effects of human resource systems on manufacturing performance and turnover. Academy of Management Journal, 37: 670-687.

Barney, J. 1991. Firm resources and sustained competitive advantage. Journal of Management, 17: 99-120.

Coyne, K.P. (January/February, 1986). Sustainable competitive advantage--What it is and what it isn't. Business Horizons, pp 54-61.

Hall, R. 1992. Strategic analysis of intangible resources. Strategic Management Journal, 13: 135-144.

Hamel, G. \& Prahalad, (1994).

Hansen, G. \& Wernerfelt, B. 1989. Determinants of firm performance: Relative importance of economic and organizational factors. Strategic Management Journal, 10: 399-411.

Huselid, M. 1995. Human resource management practices and firm performance. Academy of Management Journal, 38: 635-672.

Ichniowski, C., Shaw, K., \& Prennushi, G. 1994. The impact of human resource management practices on productivity. Columbia Business School Working Paper 015.

Jackson S.E., Schuler, R., \& Rivero, 1989. Organizational characteristics as predictors of personnel practices. Personnel Psychology, 42: 727-786.

Kochan, T., \& Osterman, P. 1994. The Mutual Gains Enterprise. Cambridge, MA: Harvard Business School Press.

Lawler, E. 1992. The Ultimate Advantage: Creating the High Involvement Organization. San Francisco, CA: Jossey-Bass.

MacDuffie, J. \& Krafcik, J. 1992. Integrating technology and human resources for highperformance manufacturing. In T. Kochan \& M. Useem (Eds.) Transforming Organizations New York: Oxford University, 210-226.

Mahoney, J. \& Pandian, J. (1992). Resource-based view within the conversation of strategic management. Strategic Management Journal, 13, 363-380.

Schuler, R. S. and Jackson, S.E. 1987. Linking competitive strategies with human resource management practices. Academy of Management Executive, 1:207-219.

Schuler, R.S. and MacMillan, I. 1984. Gaining competitive advantage through human resource practices. Human Resource Management, 23: 241-256. 
Snell, S. 1992. Control theory in strategic human resource management: The mediating effect of administrative information. Academy of Management Journal, 35: 292-327.

Snell, S., \& Youndt, M. 1995. Human resource management and firm performance: Testing a contingency model of executive controls. Journal of Management, 21: 711-738

It is important to note that the efficient production competence should be related to a cost strategy which is viewed as downplaying the importance of employees via narrow job descriptions, low skill requirements, low wages, etc. However, the role of the HR executive should still be relatively important because of the need to align the HR practices discussed above to support the core competence. 